\title{
PREMENSTRUAL DYSPHORIC DISORDER: EVALUATION, PATHOPHYSIOLOGY AND TREATMENT
}

\author{
ROGER F. HASKETT \\ Department of Psychiatry, University of Michigan Medical School, Ann Arbor, Michigan, USA
}

(Final form, December 1986)

\section{Contents}

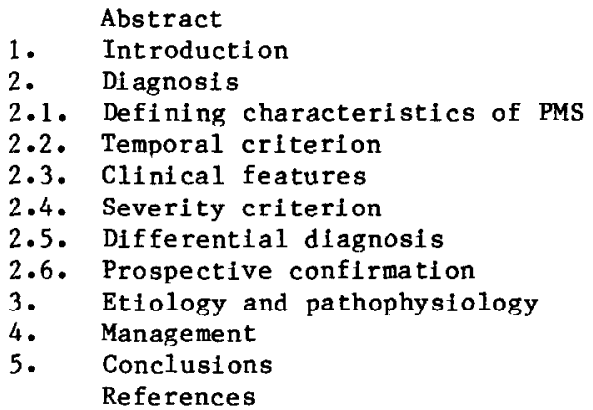

\section{Abstract}

Haskett, Roger F : Premenstrual Dysphoric Disorder (PDD): Evaluation, pathophysiology and treatment. Prog. Neuro-Psychopharmacol. \& Biol. Psychiat, 1987, 11: 129-135.

1. A small percentage of women describe a prominent dysphoric disturbance that is present during the premenstrual week, remits soon after the onset of menses and produces significant impairment in domestic, social or occupational functioning. 2. Premenstrual dysphoric disorder must be distinguished from minor premenstrual emotional changes, from dysmenorrhea and from premenstrual exacerbations of psychiatric illness. Diagnostic evaluation should include the prospective assessment of symptoms over at least two complete menstrual cycles.

3. Although the pathophysiology of premenstrual dysphoric disorder is inked to cycling of the intact hypothalamo-pituitary-gonadal axis, many studies have contained serious methodological weaknesses and no single etiological theory has received widespread support. 4. No single pharmacological treatment has been shown to be clearly more effective than placebo in controlled studies and premenstrual dysphoric disorder appears to respond favorably to most interventions in uncontrolled studies. Interruption of pituitary-ovarian cycling will alleviate premenstrual symptoms, but treatments of this type cannot be recommended for general use until potential hazards are clarified.

Keywords: diagnosis, menstrual cycle, ovarian hormones, premenstrual dysphoric disorder, premenstrual syndrome

Abbreviations: premenstrual dysphoric disorder (PDD), premenstrual syndrome (PMS), hypothalamo-pituitary-gonadal (HPG) axis

\section{Int roduction}

Recurrent emotional and behavioral changes have been noted to occur in some women before the onset of their menses. Although these phenomena have been described for many years 
(DeWees 1840), there has been a resurgence of interest in recent years. This paper will review the essentlal descriptive characteristics of premenstrual syndrome (PMS), discuss the differential diagnoses that are relevant when evaluating complaints of premenstrual distress, summarize our current understanding of the etiology and pathophyslology of PMS and critically examine the recommended treatment interventions.

More than 50 years ago, Frank (1931) graphically described a condition that he named premenstrual tension'. He reported on a group of women who "complain of a feeling of indescribable tension from ten to seven days preceding menstruation which, in most instances, continues until the time that menstrual flow occurs. These patients complain of unrest, irritability, 'like jumping out of their skin' and a desire to find relief by foolish and $i 11$ considered actions. Their personal suffering is intense and manifests itself in many reckless and sometimes reprehensible actions. Not only do they realize their own suffering, but they feel conscience-stricken towards their husbands and families, knowing well that they are unbearable in their attitude and reactions. Within an hour or two after the onset of the menstrual flow complete relief from both physical and mental tension occurs."

Today, premenstrual disturbances are receiving attention in a number of different and controversial ways. On the one hand, there are clinicians from many different disciplines who are stressing that these conditions are 'real, not imagined' and are aggressively marketing their favored treatment approaches. Conversely, other investigators question the existence of a discrete disorder and suggest that flawed research methods and negative social attitudes towards women have played a major role in generating findings of premenstrual dysfunction. Still others acknowledge that significant problems do occur in some women premenstrually but utilize a dichotomous mind-body approach that places greater emphasis on an 'organic' rather than 'psychiatric' etiology. They insist that, although emotional and behavioral change are the predominant clinical features, a psychiatric diagnosis for premenstrual syndrome will increase discrimination against women.

Frank's description highlights some of the issues that are often under-emphasized in current discussions. He was referring to women who had identified themselves as patients and who had sought his assistance in the hope that he could provide them with some relief from their distress. He identified a group of symptoms and signs that recurred regularly during a specific phase of the menstrual cycle and, according to standard nosological practice, this constituted a clinical syndrome. Since then, the literature has contained numerous reports of women presenting with similar emotional and behavioral complaints during the premenstruum. Several comprehensive reviews have been published (Steiner and Carro11, 1977; Abplanalp et al.,1980; Dalton, 1982; Clare, 1983; Halbrelch and Endicott, 1985) and these studies will not be considered in detail here. Concurrently however, many other reports have appeared that falled to detect significant premenstrual dysfunction in large groups of normal volunteers and questioned the existence of a premenstrual disorder. These findings have been discussed in reviews by Parlee (1973), Ruble (1977) and Sommer (1983). This apparent contradiction can be understood if it is recognized that, while data from normal volunteers have clearly refuted the suggestion that premenstrual dysfunction occurs in most women, these studies do not address the experiences of the sma11 percentage of women who continue to request help for premenstrual symptoms. Recent efforts to improve the definition of this clinical disturbance are aimed at facilitating research into the epidemiology, cause and effective treatments for this condition.

\section{Diagnosis}

\subsection{Defining characteristics of PMS}

Examination of the literature reveals that the term 'premenstrual syndrome' or PMS has been used to include disturbances with a wide variation in features and overall severity. There are however, two major dimensions to the defining characteristics of this syndrome: the timing of the disturbance in relation to the menstrual cycle and the typical clinical features. The diagnostic features will be examined in a discussion of the proposed criteria for a category called Premenstrual Dysphoric Disorder (PDD) that is being considered for inclusion in the revision of the Diagnostic and Statistical Manual of Mental Disorders, Third Edition (DSM IIIR). The draft criterla are listed in Table 1. 
Table 1

Diagnostic Criteria for Premenstrual Dysphorle Disorder

A. For most menstrual cycles during the past year, symptoms in B were present during the week prior to menses, and disappeared within a few days of the onset of menses.

B. At least five of the following symptoms were present for most of the tlme during each symptomatic premenstrual phase; at least one of the symptoms was efther (1), (2), (3), or (4):

(1) marked affective lability, e.g. suddenly sad, tearful, irritable, or angry

(2) persistent and marked anger or irritability

(3) feeling extremely tense, keyed up, or on edge

(4) markedly depressed mood, marked pessimisn, or self-deprecating thoughts

(5) loss of interest in usual activities, e.g. work, friends, hobbies

(6) easily tired or lack of energy

(7) subjective sense of difficulty concentrating

(8) marked change in appetite, overeating, or specific food cravings

(9) insomnia or hypersomnia

(10) other physical symproms, such as breast tenderness or swelling, headaches, joint or muscle pain, sensation of 'bloating', welght gain

c. The disturbance seriously interferes with work or with usual social activities or relationships with others.

D. The disturbance is not merely an exacerbation of the symptoms of another disorder, such as Major Depression, Panic Disorder, Dysthymic Disorder, or a Personality Disorder.

E. Criteria A, B, C, and $D$ are conflrmed by prospective dally self-ratings of at least two symptomatic cycles.

\subsection{Temporal criterion}

Criterion A emphasises the recurrent and time-limited character of this disorder. It must have been present during many menstrual cycles and predominantly affect the premenstrual week. This does not exclude those disorders that appear at midcycle, coincident with ovulation, and continue through most of the luteal phase, or those that gradually remit over the first few days of menses. The essential feature is a complete remission of the disturbance for the majority of the follicular phase. This follicular remission distinguishes a time-limited disorder like PDD from a premenstrual worsening of a chronic condition.

\subsection{C1inical features}

The clinical features of PDD are listed under criterion B. These can be grouped into three areas: emotional, behavioral and somatic. Many studies in recent years have added to the list of features seen in PMS and included virtually any symptom that has been observed during the premenstruum (Dalton 1977). These reports give insufficient attention to the distinction between typical changes and incidental findings. One attempt to characterize the specific features of a severe premenstrual disturbance utilized a group of women with severe PMS and no other evidence of psychopathology or physical illness (Haskett et a1 1980). In these women the MDQ items 'Irritability' and 'mood swings' changed most in severity between the follicular and premenstrual phases in the greatest number of subjects. 'Restlessness', 'tension', 'depression', and 'anxlety' were the next most highly ranked items of emotional change. 'Swelling of abdomen, breasts and ankles' and 'painful or 
tender breasts' were the two most commonly reported somatic changes and the next five items included a percelved difficulty in concentration, forgetfulness, distractibility and decreased efficiency. Changes in sleep, appetite and energy were also frequently mentioned. The findings of this study were incorporated into an earlier system of restrictive and operationally defined diagnostic criteria for a premenstrual tension syndrome (Steiner et al 1980).

\subsection{Severity criterion}

It must be stressed that the changes listed above were identified in a group of women who were suffering from a much more severe disturbance overall than has been found in studies of presumptively normal volunteers. Failure to recognize the importance of the severity criterion has contributed much to the controversy around the validity of a PMS diagnostic category. Epidemiological studies suggest that, despite a high prevalence of mild premenstrual changes, severe premenstrual disturbance is uncommon in the general population. For example, almost all women (98\%) attending a family practice reported some premenstrual change in at least one of 34 self-rated items (Clare 1983), but the distribution of total scores was markedly skewed and most women reported minimal disturbance. Andersch et al (1980) surveyed an urban population of 1,083 women and found that, whereas $92 \%$ reported at least one premenstrual change, severe symptoms were similarly infrequent. Seventy percent of women described the changes as mild or moderate, on $1 \mathrm{y} 10 \%$ would have welcomed treatment and severe distressing symptoms were very uncommon (2-3\%). Criterion $C$ should restrict the diagnosis of PDD to those few women in whom the premenstrual changes are associated with serious impairment of functioning.:

\subsection{Differential diagnosis}

Many emotional disorders have been noted to exacerbate during the premenstruum and criterion $D$ attempts to distinguish this situation from a disorder that is 1 imited to the premenstruum. Studies in Britain, Denmark and the United States have found that women admitted to hospital with a psychiatric diagnosis are more likely to be in the premenstrual or menstrual phases of their cycle than would be expected by chance (Dalton 1959, Kramp 1968, Janowsky et al, 1969). A recent report suggests that this interaction between menstrual cycle phase and hospitalization is related to the patient's diagnosis (Abramowitz et al 1982). Women with a diagnosis of schizophrenia did not appear to be admitted more frequently around the time of menses whereas $41 \%$ of admissions for depression occurred on the last premenstrual day or first day of menstrual flow. Although heuristically stimulating, the method of fixing phase of menstrual cycle in these studies can be criticized. The rhythm of the menstrual cycle is clearly vulnerable to disruption by environmental stress, illness and many psychotropic medications and the reported date of last menstrual period or appearance of menses in hospital are likely to be unreliable Indicators of menstrual cycle phase at the time of admission. One study that utilized endometrial histology to fix menstrual cycle phase at the time of death produced some intriguing findings (Mackinnon et al 1959). There was not only an apparent increase during the luteal phase in the proportion of deaths by suicide, but deaths due to accident and disease were also concentrated into this cycle phase.

\subsection{Prospective confirmation}

The final criterion for the diagnosis of PDD (E) deals with the discrepancies that have been noted between retrospective accounts of premenstrual complaints and prospective concurrent reports. It has been suggested that retrospective accounts may reveal more about societal attitudes and myths about the menstrual cycle than subjectively experienced changes (Abplanalp et al 1980, Ruble 1977, Ruble and Brooks-Gunn 1979). In one study, a group of women with a history of severe premenstrual disturbance were divided according to whether their concurrent self-reports in the follicular and premenstrual phases confirmed that their disturbance was both severe and time-1imited (Haskett and Abplanalp 1983). Separate daily ratings revealed that only the subgroup with a confirmed disorder actually experienced a significant increase in negative mood scores during the premenstruum compared to very low levels of symptomatology during the other phases of the cycle. Concurrent daily self-ratings over at least two complete cycles will permit the evaluator to distinguish between a diagnosis of PDD and premenstrual exacerbations of other disorders, or psychopathology that is unrelated to the premenstruum. 


\section{Etiology and Pathophysiology}

Many hypotheses have been considered in attempts to explain the origins of premenstrual disorder. Several excellent summaries of this literature have examined the evidence supporting or refuting each theory (Steiner and Carroll 1977, Reid and Yen 1980, Rausch and Janowsky 1982) and, since no single explanation has been substantiated, these studies will not be reviewed in detall in this paper.

Despite the lack of an identified mechanism, there is an obvious link between premenstrual changes and an intact, cycling hypothalamo-pituitary-gonadal (HPG) axis. The onset of the disorder occurs after puberty, the disturbance remits during pregnancy, may persist after hysterectomy if functioning ovaries remain, but will cease after oophorectomy or spontaneous menopause. It is not surprising therefore, to find that many hypotheses have attempted to $11 \mathrm{nk}$ the appearance of premenstrual symptoms to an abnormal absolute level or ratio of hormones during the menstrual cycle. These include estrogen excess, progesterone deficiency, altered estrogen/progesterone ratio and hyperprolactinemia. Unfortunately these hormonal abnormalities have not been consistently demonstrated and many findings that appeared to support these etiological relationships were obtained from studies with serious methodological weaknesses. For example, subject selection criteria were vague or imprecise, appropiate control populations were not included, menstrual cycle phase was defined by unreliable markers and endocrine function was inferred from single blood samples. In addition, most theories fail to account for the absence of symptoms at other times when similar hormonal 'abnormalities' are present.

The regulation of the menstrual cycle involves a complex series of interactions between brain neurotransmitter systems, pituitary gonadotropins and ovarian steroids. Instead of representing the cause of the observed psychopathology, altered levels of peripheral hormones may be markers of changes in the central components of the HPG axis and recently, more attention has been directed towards the temporal patterns of circulating peripheral hormones rather than the absolute levels. Changes in peripheral hormone levels may be closely linked to fluctuations in central neurotransmitter systems that, not only particlpate in the regulatory mechanisms of the menstrual cycle, but are capable of altering emotions and behavior (Reid 1983). Further studies, in carefully characterized populations of women with PMS, should search for abnormal functioning in the dynamic systems that have been shown to be involved in the regulation of the normal menstrual cycle.

\section{Management}

The 1iterature on the management of premenstrual disorder contains results that are just as contradictory and inconclusive as those from investigations into the cause of this disturbance. Many of the same methodological concerns are relevant. Although progesterone and pyridoxine have been separately promoted as effective treatments for PMS, appropiately designed studies have been unable to show a consistent effect. There is minimal evidence to support the use of lithium or other antidepressants unless the woman is also suffering from a major affective disorder that requires treatment. Interruption of HPG axis cycling with danazol (Day 1979, Dennerstein et al 1983) or a gonadotropin-releasing-hormone agonist (Muse et a1 1984) will produce a remission in the premenstrual disturbance, but this form of intervention cannot be recommended for the general treatment of PMS until its potential. hazards have been more thoroughly assessed. Trials of treatment with oral contraceptives have yielded inconsistent results and some women reported a worsening of their symptoms (Cullberg 1972).

PMS appears to respond favorably to most interventions in uncontrolled studies and there is a prominent placebo effect in almost all controlled studies (Smith 1975). There is also evidence to suggest that monitoring the clinical features is associated with a decrease in the level of the disturbance (Harrison et a1 1984). The concurrent ratings, an essential part of the diagnostic evaluation, are therefore also the first form of intervention. This strategy has the advantage of demonstrated efficacy and minimal risk. In addition, many women report that some dietary components, such as caffeine-containing foods and drinks, and foods with high salt content, aggravate their premenstrual symptoms. Although the scientific support for these influences is lacking, simple changes in diet have a low risk and may be of benefit. 


\section{Conclusions}

In summary, the diagnosis of PDD depends upon the identification of a time-1imited premenstrual syndrome that is comprised of the typical clinical features. The overall level of disturbance must meet a severity criterion during the premenstrual phase when the disorder is present and must also meet a 'normality' criterion during the follicular phase when the disorder has remitted. The principle differential diagnoses are premenstrual exacerbations of other psychiatric disorder, dysmenorrhea and mild subjective premenstrual changes that are not associated with dysfunction. Although the pathophysiology of this disorder remains unclear, future studies will continue to examine the dynamic changes in the regulatory systems of the HPG axis instead of simply focussing on a search for abnormal levels of peripheral hormones. The management of PMS must acknowledge that there is still no specific pharmacological treatment with demonstrated efficacy and the choice of any intervention should be strongly influenced by the possibility of serious risks or sideeffects.

\section{References}

ABLANALP, J.M., DONNELLY, A.F. and ROSE, R.M. (1979) Psychoendocrinology of the menstrual cycle: 1. Enjoyment of daily activities and moods. Psychosom. Med. 41: 587-604.

ABLANALP, J.M., HASKETT, R.F. and ROSE, R.M. (1980) The premenstrual syndrome. Psychlat. C1In. N. Am. 3: 327-347.

ABRAMOWITZ, E.S., BAKER, A.H. and FLEISCHER, S.F. (1982) Onset of depressive psychiatric crises and the menstrual cycle. Am J. Psychiat. 139: 475-478.

ANDERSCH, B., WENDESTAM, C., HAHN, L. and OHMAN, R. (1980) Prevalence of premenstrual symptoms in a Swedish urban population. In, Epidemiological, hormonal and water balance studies on premenstrual tension. B. Andersch (ed). Thesis, University of Goteburg.

CLARE, A.W. (1983) Psychiatric and social aspects of premenstrual complaint. Psychol. Med. Monograph Suppl. 4 .

CULLBERG, J. (1972) Mood changes and menstrual symptoms with different gestagen/estrogen combinations. Acta. Psychiat. Scand. Suppl. 236: 1-84.

DALTON, K. (1959) Menstruation and acute psychiatric illnesses. Br. Med. J. 1: $148-149$. DALTON, K. (1977) The premenstrual syndrome and progesterone therapy. W. Heinemann Medica1 Books, London.

DALTON, K. (1982) Premenstrual tension: An overview. In, Behavior and the Menstrual

Cycle. R.C. Friedman (ed.), M. Dekker, New York. pp. 217-242.

DAY, J. (1979) Danazol and the premenstrual syndrome. Postgrad. Med. J. Suppl. No. 5. 55: 87-89.

DENNERSTEIN, L., JUDD, F, and DAVIES, B. (1983) Psychosis and the menstrual cycle. Med.

J. Aust. $1: 77-92$.

DEWEES, W.P. (1840) A Treatise on the Diseases of Females. Lee and Blanchard,

Philadelphia.

FRANK, R.T. (1931) The hormonal causes of premenstrual tension. Arch. Neurol. Psychiat. 26: 1053-1057.

HALBREICH, U. and ENDICOTT, J. (1985) Methodological issues in studies of premenstrual changes. Psychoneuroend ocrinology 10: 15-32.

HARRISON, W.M., ENDICOTT, J., RUBKIN, J.G. and NEE, J. (1984) Treatment of premenstrua1 dysphoric changes: Clinical outcome and methodological implications. Psychopharm. Bu11. 20: 118-122.

HASKETT, R.F., STEINER, M., OSMUN, J.N. and CARROLL, B.J. (1980) Severe premenstrual tension: Delineation of the syndrome. Biol. Psychiat. 15: 121-139.

HASKETT, R.F. and ABPLANALP, J.M. (1983) Premenstrual tension syndrome: Diagnostic criteria and selection of research subjects. Psychiat. Res. 9: 125-138.

JANOWSKY, D.S., GORNEY, R., CASTELNUOVO-TEDESCO, P. and STONE, C.B. (1969) Premenstrualmenstrual increases in psychiatric hospital admission rates. Am. J. Obstet. Gynecol. 103: 189-191.

KRAMP, J.L. (1968) Studies on the premenstrual syndrome in relation to psychiatry. Acta. Psychiat. Scand., Suppl., 203: 261-267.

MACKINNON, I.L., MACKINNON, P.C.B.and THOMSON, A.D. (1959) Lethal hazards of the luteal phase of the menstrual cycle. Br. Med. J. 1: 1015-1017.

MUSE, K.H., CETEL, N.S., FUTTERMAN, L.A. and YEN, S.S.C. (1984) The premenstrual syndrome: Ef fects of 'medical ovariectomy'. N. Engl. J. Med. 311: 1345-1349.

PARLEE, M.B. (1973) The premenstrual syndrome. Psychol. Bull. 80: 454-465. 
RAUSCH, J.L. and JANOWSKY, D.S. (1982) Premenstrual tension: Etiology. In, Behavior and the Menstrual Cycle. R.C. Friedman (ed.), M. Dekker, New York. pp. 397-427.

REID, R.L. (1983) Endogenous opioid activity in premenstrual syndrome. Lancet 2: 786 .

REID, R.L. and YEN, S.S.C. (1981) Premenstrual syndrome. Am. J. Obstet. GynecoI. 139: 85104.

RUBLE, D.N. (1977) Premenstrual symptoms: A reinterpretation. Science 197: 291-292.

RUBLE, D.N. and BRoOkS-GUNN, J. (1979) Menstrual symptoms: A social cognition analysis.

J. Behav. Med. 2: 171-193.

SMITH, S.L. (1975) Mood and the menstrual cycle. In, Topics in Endocrinology. E.J. Sachar (ed), Grune and Stratton, New York.

SOMMER, B. (1983) How does menstruation affect cognitive competence and

peychophysiological response? Women and Health 8 : 53-90.

STEINER, M. and CARROLL, B.J. (1977) The psychobiology of premenstrual dysphoria: Review of theories and treatments. Psychoneuroendocrinology 2: 321-335.

STEINER, M., HASKETT, R.F. and CARROLL, B.J. (1980) Premenstrual tension syndrome. The development of research diagnostic criteria and new rating scales. Acta Psychlat. Scand. 62: $177-190$.

Inquiries and reprints requests should be addressed to:

Dr. Roger F, llaskett

Department of Psychiatry

University of Michigan Medical School

Ann Arbor, Michigan 48109

USA 